\title{
Concurrent Thermochemoradiotherapy for Brain High-Grade Glioma
}

\author{
A. I. Ryabova ${ }^{1, a)}$, V. A. Novikov ${ }^{1}$, E. L. Choinzonov ${ }^{1,2}$, O. V. Gribova ${ }^{1,3}$, \\ Zh. A. Startseva ${ }^{1}$, E. E. Bober ${ }^{1}$, I. G. Frolova ${ }^{1}$, and A. V. Baranova ${ }^{3}$ \\ ${ }^{1}$ Tomsk Cancer Research Institute, Tomsk, 634050 Russia \\ ${ }^{2}$ Siberian State Medical University, Tomsk, 634050 Russia \\ ${ }^{3}$ National Research Tomsk Polytechnic University, Tomsk, 634050 Russia \\ ${ }^{\text {a) }}$ Corresponding author: ranigor@mail.ru
}

\begin{abstract}
Despite the achievements in the current strategies for treatment, the prognosis in malignant glioma patients remains unsatisfactory. Hyperthermia is currently considered to be the most effective and universal modifier of radiotherapy and chemotherapy. Preliminary treatment outcomes for 28 patients with newly diagnosed (23) and recurrent (5) high-grade gliomas were presented. All the patients received multimodality treatment including surgery, thermochemoradiotherapy followed by 4 cycles of adjuvant chemotherapy. All the patients endured thermochemoradiotherapy well. A complication, limited skin burn (II stage), was diagnosed in two cases and treated conservatively without treatment interruption. A month after thermochemoradiotherapy the results were as follows: complete regression was achieved in 4 cases, partial regression in 4 cases, stable disease in 14 cases and disease progression in 6 cases (one of them is pseudoprogression). After completing the adjuvant chemotherapy 2 more patients demonstrated complete response and 1 patient had disease progression. Introduction of local hyperthermia in multimodal therapy of malignant glioma does not impair the combined modality treatment tolerability of patients with malignant gliomas. A small number of studied patients and short follow-up time do not allow making reliable conclusions about the impact of local hyperthermia on the treatment outcomes; however, there is a tendency towards the increase in disease-free survival in the patients with newly diagnosed malignant gliomas.
\end{abstract}

\section{INTRODUCTION}

Epidemiological survey proves that over the last 10-20 years there has been a steady increase in brain tumor disease all over the world. According to statistical analysis malignant glioma (MG) is estimated to affect 5-8 people per 100,000 in the general population [1]. In spite of diagnostics and treatment improvement, the MG mortality rate is still high, and the treatment outcomes are unsatisfactory. With modern standards of medical services, the median survival for patients with the most malignant glioma (G4) is 12-15 months, despite intensive multimodal therapy [2].

Modern standard management of MG patients is based on a multidisciplinary approach and involves maximal tumor resection with the least possible postoperative neurological deficits, adjuvant (chemo) radiotherapy followed by adjuvant chemotherapy. Different approaches have been used to enhance successful treatment outcomes and overcome the radioresistance of high-grade gliomas. They are as follows: increasing a total radiation therapy dose, introducing alternative fractionation schemes, intraoperative radiotherapy, interstitial brachytherapy, and radiosurgery. All of them have failed to be successful. Though some small clinical study proved the survival rate improvement, further randomizing studies showed no benefits for MG patients [3]. Randomizing studies related to radiosensitizer application (Mizonidazole, Metronidazole, Bromodeoxyuridine, and Tirapazamine) did not show the expected results in overcoming radioresistance of high-grade gliomas. Disease-free and overall survival did not improve [1].

The contemporary approach regards hyperthermia (HT) as the most effective and universal modifier of radiotherapy and chemotherapy that is able to enhance treatment efficiency by a factor of $1.5-2.5$ [1, 4]. The 
benefits of combination of hyperthermia with radiotherapy and certain chemotherapy drugs have been studied since the 1970s. It was shown that a heated tumor is forced to higher metabolism, which, due to impaired blood supply, empties the cellar's energies. The lactic acid content increases causing electrolyte imbalance that slow down or even impede DNA replication. The complementary effect of (chemo) radiotherapy and HT is conditioned by the fact that the direct HT impact is much stronger on the cells in the hypoxic tissue, low-pH range and in the S-phase of the cellcycle, which are relatively radio-resistant [5]. Besides, HT increases cytotoxic radiation effects, particularly by interfering with the cellular repair system as a result of denaturing the DNA repair system enzymes. Moderate hyperthermia also causes tumor perfusion thus enhancing tumor tissue oxygenation, which results in radiosensitivity improvement. HT can promote an anti-tumour response by stimulating the immune system through an increased surface expression of immune-related cell markers (MHC class I, etc.) and the stimulation of the synthesis of heat shock proteins. Exposure to HT can result in antitumor response due to immune system stimulated by upregulation of the surface markers related to the immune cells (MHC class 1 etc.) and heat shock protein synthesis [6].

Local electromagnetic hyperthermia is the most suitable method for radiosensibility. It can be of multiple uses, non-invasive, and does not require additional pharma drugs to focus heat energy in a tumor. The heating energy is automatically focused in tumor tissues. Due to different metabolic rates (Fig. 1) the tumor has higher electrical conductivity, which results in tumor tissue heating up faster than healthy one. The power and the current frequency are chosen so that the extracellular fluid and cell membrane are primarily heated. The temperature increasing, the tumor tissue keeps on heating due to impaired blood supply, while healthy tissue is effectively cooled by the blood flow. As a result, the temperature difference is formed on both sides of the cell membrane, eventually damaging the membrane and leading to death of the tumor cells [6].

Nowadays local hyperthermia (LHT) is extensively used in multimodal treatment of patients with recurrent malignant gliomas. It is also applied alone in palliative therapy of tumors resistant to radiation and chemotherapy. A great number of clinical studies proved relative safety and effectiveness of LHT in the treatment of malignant gliomas. However, some patients developed serious complications [5]. Moreover, the published studies [4, 6, 7] provide no evaluation of immediate and long-term results of adjuvant chemoradiotherapy with temozolomide/lomustine (CCNU) combined with LHT in the patients with newly diagnosed MG. The purpose of our research was to assess treatment rates and acceptability of MG treatment in the course of radiosensibility enhanced by LHT.

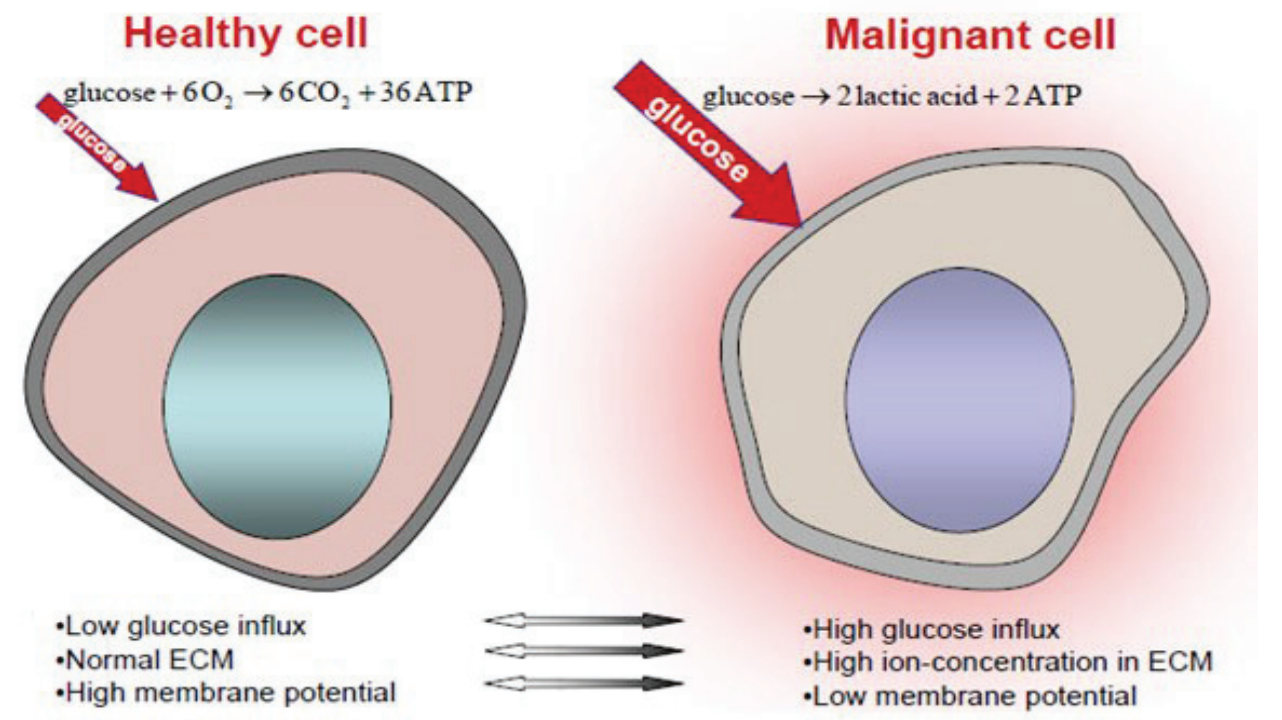

Szasz A. et al., 2013

FIGURE 1. Difference in healthy and malignant cells [6] 


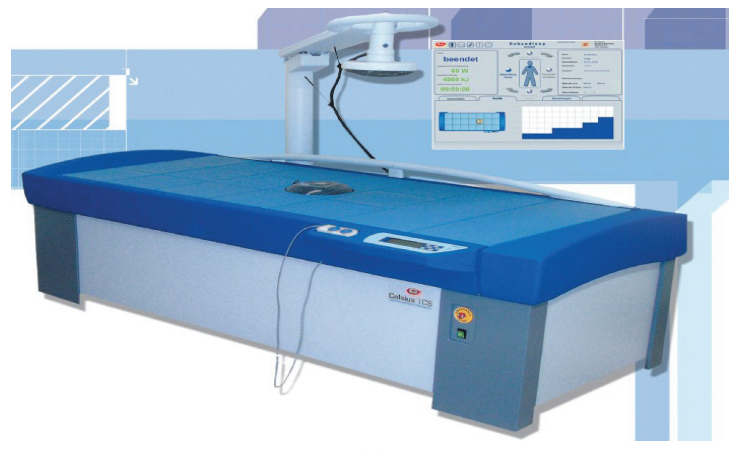

(a)

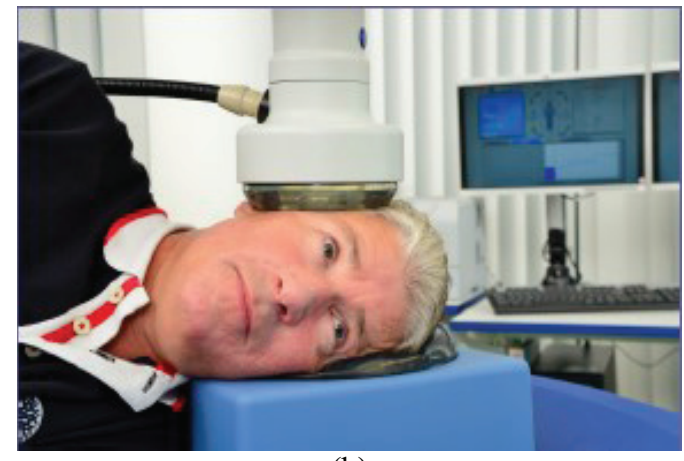

(b)

FIGURE 2. The Celsius TCS hyperthermia system: (a) general view of the apparatus, (b) local hyperthermia session in brain area

\section{MATERIALS AND METHODS}

In Tomsk Cancer Research Institute (Tomsk, Russia), the method of multimodality treatment including LHT combined with chemoradiotherapy was developed for treating the patients with high-grade glioma. Twenty eight patients with high-grade gliomas received multimodality treatment including surgery, LHT, radiotherapy and chemotherapy. The tumor was removed within sight of unchanged brain tissue using micro-neurosurgical techniques. 23 cases out of 28 were newly diagnosed MG, 5 cases were recurrent MGs (after the combined multimodal treatment).

Local hyperthermia was performed 2 times a week (8-10 sessions) by a system for deep hyperthermia Celsius TCS (Fig. 2), which uses electromagnetic waves with a frequency of $13.56 \mathrm{MHz}$ (radio waves) to transfer energy based on the principle of capacitive coupling.

The heated area exceeded the maximum diameter of the tumor by at least $3 \mathrm{~cm}$ at the surface location and increased in proportion to the depth of its occurrence. Heating was gradually carried out by increasing the capacity, guided by the patient tolerability. Direct tumor hyperthermia was performed: at maximum temperature of $41-42^{\circ} \mathrm{C}$ for 20-60 min, and at a temperature above $42^{\circ} \mathrm{C}$ - for 10-30 min (Fig. 3).

Radiation therapy was carried out by means of a Theratron Equinox device with photon energy of $1.25 \mathrm{MeV}$ in a standard dose fractionation regimen-2.0 Gy single dose, 5 times a week to a total dose of 60 Gy in the patients with newly diagnosed high-grade gliomas and to a total dose of $40 \mathrm{~Gy}$ in reccurent glioma patients. The interval between LHT and radiation therapy was $20-40 \mathrm{~min}$.

\begin{tabular}{|c|c|c|c|c|c|c|c|c|c|c|c|}
\hline \multicolumn{2}{|c|}{ 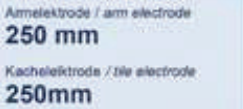 } & 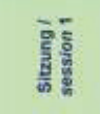 & 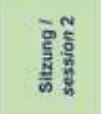 & 啹施 & 总容 & 哣 & 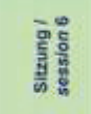 & 㼨产 & 胀步 & कू. & 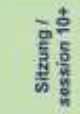 \\
\hline \multicolumn{2}{|c|}{$\begin{array}{l}\text { Kuhitemperatur / } \\
\text { cooling temperature }\end{array}$} & $12^{\circ} \mathrm{C}-16^{\circ} \mathrm{C}$ & $12^{\circ} \mathrm{C} \cdot 16^{\circ} \mathrm{C}$ & $12^{\circ} \mathrm{C}-16^{\circ} \mathrm{C}$ & $8^{\circ} \mathrm{C}-12^{\prime} \mathrm{C}$ & $\mathrm{B}^{\circ} \mathrm{C}$ & $B \times C$ & $88 \mathrm{C}$ & $8^{\circ} \mathrm{C}$ & $8^{\circ} \mathrm{C}$ & $8 \times C$ \\
\hline 1. Stufe & $\begin{array}{l}\text { Daver I duration } \\
\text { Leistung/ power }\end{array}$ & ${ }_{40 \mathrm{Win}}^{20}$ & $\begin{array}{l}20 \mathrm{~min} \\
50 \mathrm{w}\end{array}$ & $\begin{array}{l}20 \mathrm{~min} \\
60 \mathrm{~W}\end{array}$ & $\frac{20 \min }{70 \mathrm{w}}$ & ${ }_{80 \mathrm{~W}}^{20 \mathrm{~min}}$ & ${ }_{80 \mathrm{w}}^{20 \min }$ & ${ }_{80 \mathrm{Win}}^{20 \mathrm{~m}}$ & $\begin{array}{l}20 \mathrm{~min} \\
80 \mathrm{~W}\end{array}$ & ${ }_{80 \mathrm{~W}}^{20 \mathrm{~min}}$ & $\begin{array}{l}20 \mathrm{~min} \\
80 \mathrm{~W}\end{array}$ \\
\hline 2. Stufe & $\begin{array}{l}\text { Dauer / durabon } \\
\text { Lesistung / power }\end{array}$ & $\begin{array}{l}10 \mathrm{~min} \\
60 \mathrm{w}\end{array}$ & $\begin{array}{l}10 \mathrm{~min} \\
70 \mathrm{w}\end{array}$ & $\begin{array}{l}10 \mathrm{~min} \\
80 \mathrm{w}\end{array}$ & $\begin{array}{l}10 \mathrm{~min} \\
90 \mathrm{~W}\end{array}$ & $\begin{array}{l}10 \min \\
100 \mathrm{w}\end{array}$ & $\begin{array}{l}10 \mathrm{~min} \\
100 \mathrm{~W}\end{array}$ & $\begin{array}{l}10 \mathrm{~min} \\
100 \mathrm{w}\end{array}$ & $\begin{array}{l}10 \min \\
100 \mathrm{~W}\end{array}$ & $\begin{array}{l}10 \min \\
100 w\end{array}$ & $\begin{array}{l}10 \mathrm{~min} \\
100 \mathrm{~W}\end{array}$ \\
\hline 3. Stufe & $\begin{array}{l}\text { Daver / duration } \\
\text { Leistung / powar }\end{array}$ & $\begin{array}{l}10 \min \\
70 \mathrm{w}\end{array}$ & $\begin{array}{l}10 \mathrm{~min} \\
80 \mathrm{w}\end{array}$ & $\begin{array}{l}10 \mathrm{~min} \\
100 \mathrm{w}\end{array}$ & $\begin{array}{l}10 \mathrm{~min} \\
110 \mathrm{w}\end{array}$ & $\begin{array}{l}10 \min \\
120 \mathrm{w}\end{array}$ & $\begin{array}{l}10 \min \\
120 w\end{array}$ & $\begin{array}{l}10 \min \\
120 \mathrm{w}\end{array}$ & $\begin{array}{l}10 \mathrm{~min} \\
120 \mathrm{~W}\end{array}$ & $\begin{array}{l}10 \mathrm{~min} \\
120 \mathrm{~W}\end{array}$ & $\begin{array}{l}10 \mathrm{~min} \\
120 \mathrm{~W}\end{array}$ \\
\hline 4. Stufe & $\begin{array}{l}\text { Davoer / duration } \\
\text { Lestung / power }\end{array}$ & $\begin{array}{l}10 \mathrm{~min} \\
80 \mathrm{~W}\end{array}$ & $\begin{array}{l}10 \mathrm{~min} \\
100 \mathrm{w}\end{array}$ & $\begin{array}{l}10 \mathrm{~min} \\
120 \mathrm{w}\end{array}$ & $\begin{array}{l}10 \mathrm{~min} \\
130 \mathrm{w}\end{array}$ & $\begin{array}{l}10 \mathrm{~min} \\
140 \mathrm{w}\end{array}$ & $\begin{array}{l}10 \mathrm{~min} \\
140 \mathrm{w}\end{array}$ & $\begin{array}{l}10 \mathrm{~min} \\
140 \mathrm{w}\end{array}$ & $\begin{array}{l}10 \mathrm{~min} \\
140 \mathrm{~W}\end{array}$ & $\begin{array}{l}10 \mathrm{~min} \\
140 \mathrm{w}\end{array}$ & $\begin{array}{l}10 \mathrm{~min} \\
140 \mathrm{w}\end{array}$ \\
\hline 5. Stufe & $\begin{array}{l}\text { Davor / duration } \\
\text { Leistung / powert }\end{array}$ & $\begin{array}{l}10 \min \\
100 \mathrm{w}\end{array}$ & $\begin{array}{l}10 \mathrm{~min} \\
110 \mathrm{~W}\end{array}$ & $\begin{array}{l}10 \mathrm{~min} \\
\text { max, } \\
\text { thenbin } \\
\text { Powser }\end{array}$ & $\begin{array}{l}10 \mathrm{~min} \\
\text { max. } \\
\text { tolerster } \\
\text { Powwer }\end{array}$ & 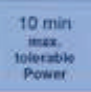 & 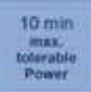 & 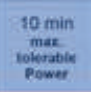 & $\begin{array}{l}10 \mathrm{~min} \\
\text { max. } \\
\text { tuleratit } \\
\text { Pown t }\end{array}$ & 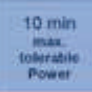 & $\begin{array}{c}10 \mathrm{~min} \\
\text { max: } \\
\text { talerablet } \\
\text { Poester }\end{array}$ \\
\hline & $\begin{array}{l}\text { gebene Energiel } \\
\text { appled energy }\end{array}$ & $234 \mathrm{~kJ}$ & $-280 \mathrm{~kJ}$ & $-335 \mathrm{~kJ}$ & $-385 \mathrm{~kJ}$ & $3410 \mathrm{~kJ}$ & $>410 \mathrm{~kJ}$ & $3410 \mathrm{~kJ}$ & $>410 \mathrm{~kJ}$ & $>410 \mathrm{~kJ}$ & $2410 \mathrm{~kJ}$ \\
\hline Sitzungs: & uet / session time & $60 \mathrm{~min}$ & $60 \mathrm{~min}$ & $60 \mathrm{~min}$ & $60 \mathrm{~min}$ & $60 \mathrm{~min}$ & $60 \mathrm{~min}$ & $60 \mathrm{~min}$ & $60 \mathrm{~min}$ & $60 \mathrm{~min}$ & $60 \mathrm{~min}$ \\
\hline
\end{tabular}

FIGURE 3. Examples for treatments with Celsius TCS System 


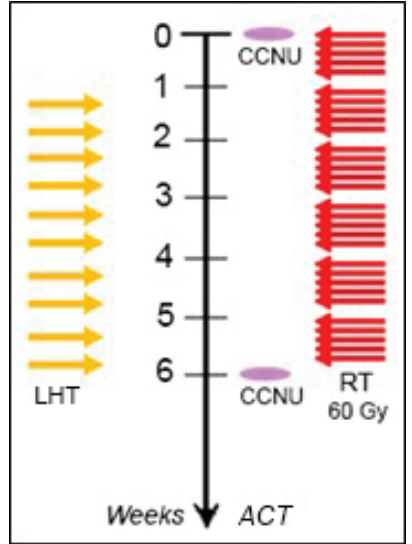

(a)

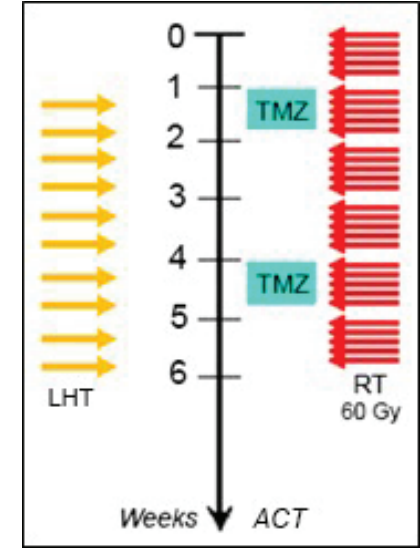

(b)

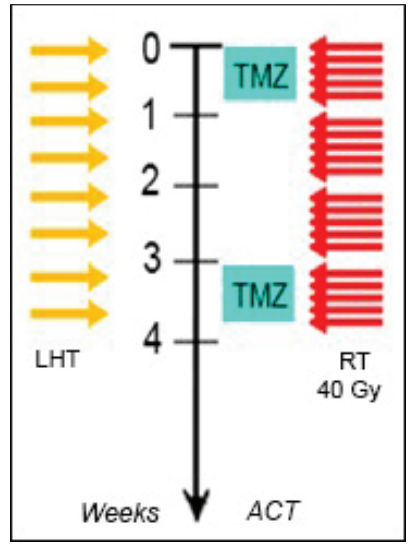

(c)

FIGURE 4. Treatment protocols: (a) newly diagnosed anaplastic glioma, (b) newly diagnosed glioblastoma, (c) reccurent high-grade glioma

All patients received two concomitant sessions of chemotherapy during the course of radiation therapy combined with LHT and four cycles of adjuvant chemotherapy. The patients with newly diagnosed glioblastoma received chemotherapy with temozolomide at a dose of $200 \mathrm{mg} / \mathrm{m}^{2}$, once daily for 5 days of a 28 -day treatment cycle. The patients with newly diagnosed anaplastic glioma received lomustine (CCNU) at a dose of $70-100 \mathrm{mg} / \mathrm{m}^{2}$ once per six weeks. Reccurent glioma patients were treated with temozolomide at a dose of $200 \mathrm{mg} / \mathrm{m}^{2}$, once daily for 5 days of a 28-day treatment cycle (Fig. 4).

Contrast-enhanced MRI brain scans were obtained to assess immediate tumor response to thermochemoradiotherapy (RANO criteria). Follow-up contrast-enhanced MRI was obtained every 3 months during the first year, every 6 months thereafter and in the event of new neurological symptoms.

\section{RESULTS}

In the group of newly diagnosed high-grade gliomas histological examination revealed glioblastomas in 15 cases, anaplastic glioma - in 8 cases. Reccurent anaplastic glioma was diagnosed in 3 cases, reccurent glioblastoma-in 2 cases. Contrast-enhanced MRI assessed the extent of surgical tumor removal as partial resection in 15 patients, subtotal resection in 7 and total resection in 6 patients. The Karnofsky Performance Scale Index on hospital admission varied from 40 to $90 \%$.

All the patients endured the treatment adequately - there was no case of cerebral symptoms and convulsive disorder development. Steady development of focal neurologic symptoms (pyramidal insufficiency increase) that could not be arrested with intensive antiedema therapy was observed in two cases. In the first case it was conditioned by disease progression in the course of the treatment, in the other case the symptoms developed after chemotherapy with temozolomide (without MRI signs of tumor progression). 24 patients needed receiving glucocorticoid therapy, there was no need in such therapy in 4 cases with newly diagnosed anaplastic astrocytomas. During the treatment course the Karnofsky Performance Scale Index of 8 patients increased.

The short-term results of thermochemoradiotherapy showed complete regression in 4 cases in the group of newly diagnosed tumors. Partial regression was registered in both newly diagnosed and recurrent tumor groups - 4 cases total. In most cases the therapy resulted in tumor stabilization (14 cases), 6 cases referred to tumor progression (Fig. 5). Upon that, 1 tumor progression was diagnosed during the chemo-radiotherapy combined with LHT (with the dose of 42 Gy and 7 sessions of LHT). The follow-up MRI showed evidence of tumor progression without neurologic impairment increase in 5 cases. Afterwards, 1 of the 5 cases was distinguished as psydoprogression, since the tumor increase in size was conditioned by early radiation necrosis.

The follow-up monitoring registered a continued tumor growth with newly diagnosed anaplastic astrocytoma 3 months after chemoradiotherapy combined with LHT. A complete regression was diagnosed after a course of adjuvant chemotherapy in 1 case. 


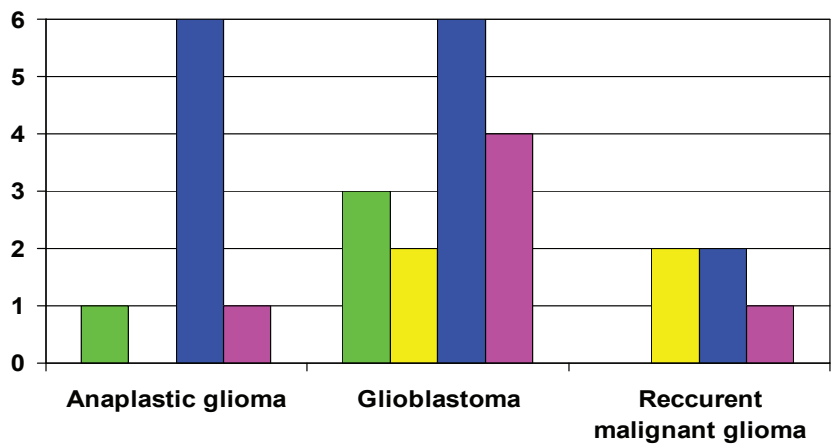

$\square$ Complete regression

$\square$ Partial regression

$\square$ Stabilization

$\square$ Tumor progression

FIGURE 5. Short-term result of the thermochemoradiotherapy

One more case was of tumor regress 1 year after the multimodality treatment completion (Fig. 6). Tumor progression was diagnosed in all cases of the recurrent tumor group, a continued tumor growth occurring within 110 months.

Two patients with the newly diagnosed tumor were lost for follow up 1 month after the termochemoradiotherapy (3 months after surgical therapy) with the effect of complete or partial tumor regression. All the cases of the recurrent tumor group were fatal within 4-14 months, with median survival of 7 months. There was no fatal case in the group of newly diagnosed MG. The observation period for the patients with newly diagnosed MG ranged from 3 to 33 months, with the median follow up being 4 months.

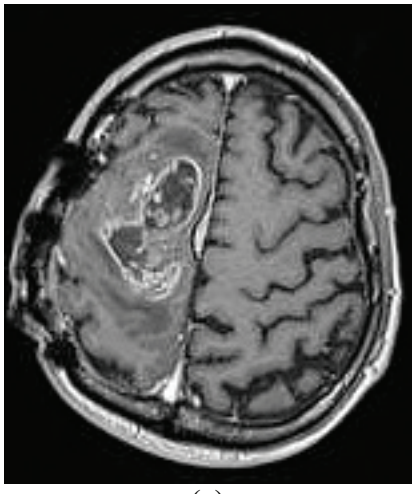

(a)

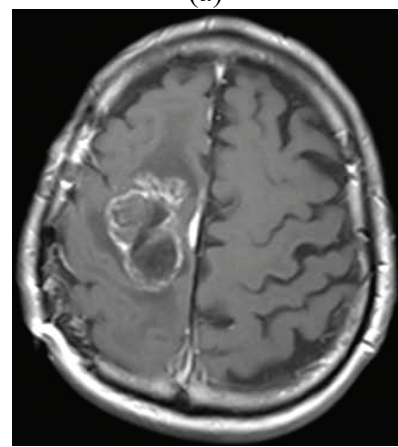

(c)

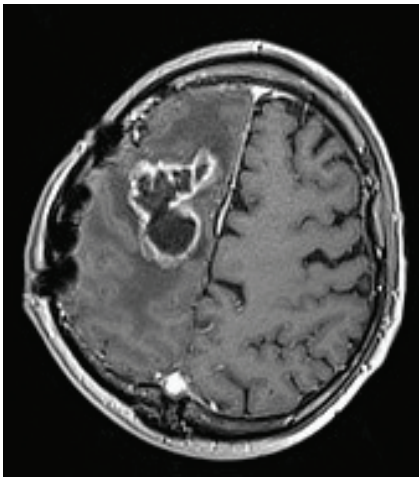

(b)

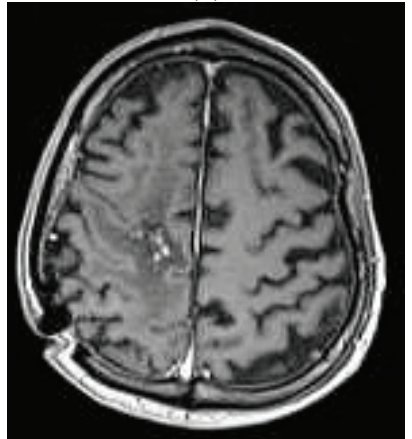

(d)

FIGURE 6. Contrast-enhanced MRI brain scans of patient H.: (a) tumor progression 2 months after sub-total surgery, (b) stabilization in a month after course of thermochemoradiotherapy, (c) process stabilization after completion of adjuvant chemotherapy, (d) partial regression 19 months after the course of concurrent thermochemoradiotherapy (24 months after surgical treatment) 


\section{CONCLUSION}

Based on the data obtained, we can conclude that local hyperthermia in combination with chemoradiotherapy does not impair the tolerability of the combined modality treatment of patients with malignant gliomas. A small number of the patients under study and short follow-up time do not allow making reliable conclusions about the impact of local hyperthermia on the treatment outcomes; however, there is a tendency towards the increase in disease-free survival in the patients with newly diagnosed malignant gliomas.

\section{ACKNOWLEDGMENTS}

The study reported in this article was conducted according to accepted ethical guidelines involving research in humans and/or animals and was approved by an Ethical Committee of Tomsk Cancer Research Institute

The study is compliant with the ethical standards as currently outlined in the Declaration of Helsinki.

All individual participants discussed in this study, or for whom any identifying information or image has been presented, have freely given their informed written consent for such information and/or image to be included in the published article.

The work has been financially supported by the Fundamental Research Program of the Russian Academy of Sciences, project No. 093.

\section{REFERENCES}

1. E. L. Choinzonov, O. V. Gribova, Zh. A. Startseva, et al., Current approaches to chemoradiotherapy for malignant gliomas, Bulletin Siberian Med. 13(3), 119-125 (2014).

2. A. A. Yin, J. X. Cheng, X. Zhang, and B. L. Liu, The treatment of glioblastomas: a systematic update on clinical phase III trials, Critical Rev. Oncology/Hematology 87(3), 265-282 (2013).

3. J. P. Kirkpatrick, F. F. Yin, and J. H. Sampson, Radiotherapy and radiosurgery for tumors of the central nervous system, Surgical Oncology Clinics North Am. 22(3), 445-461 (2013).

4. V. S. Ulashchik, The role of local hyperthermia in oncology: applications of a magnetic field, laser radiation, and ultrasound, Probl. Balneol. Physiother. Med. Phys. Training. 91(2), 48-57 (2014).

5. W. Lee Titsworth, G. J. Murad, B. L. Hoh, and M. Rahman, Fighting fire with fire: the revival of thermotherapy for gliomas, Anticancer Res. 34(2), 565-574 (2014).

6. A. Szasz, N. Iluri, and O. Szasz, in Hyperthermia, edited by N. G. Huilgol (InTech, 2013), http://www. intechopen.com/books/hyperthermia/local-hyperthermia-in-oncology-to-choose-or-not-to-choose-.

7. J. Sun, M. Guo, H. Pang, et al., Treatment of malignant glioma using hyperthermia, Neural Regeneration Res. 8(29), 2775-2782 (2013). 